\title{
Degree of family cohesion and social class are associated with the number of cavitated dental caries in adolescents
}

\section{Laio da Costa DUTRA ${ }^{(a)}$ iD \\ Érick Tássio Barbosa NEVES(a) \\ Larissa Chaves Morais de LIMA(a) \\ Monalisa Cesarino GOMES(a) \\ Franklin Delano Soares FORTE(b) iD \\ Saul Martins PAIVA(c) \\ Mauro Henrique Nogueira \\ Guimarães de ABREU(c) iD}

Fernanda Morais FERREIRA(c)

Ana Flávia GRANVILLE-GARCIA(a) iD

(a) Universidade Estadual da Paraíba - UEPB, Department of Dentistry, Campina Grande, PB, Brazil.

(b) Universidade Federal da Paraíba - UFPB, Department of Dentistry, João Pessoa, PB, Brazil.

(c) Universidade Federal de Minas Gerais UFMG, School of Dentistry, Department of Pediatric Dentistry and Orthodontics, Belo Horizonte, MG, Brazil.

Declaration of Interests: The authors certify that they have no commercial or associative interest that represents a conflict of interest in connection with the manuscript.

Corresponding Author:

Ana Flávia Granville-Garcia

Email: anaflaviagg@hotmail.com

https://doi.org/10.1590/1807-3107bor-2020.vol34.0037

Submitted: July 26, 2019

Accepted for publication: January 10, 2020

Last revision: March 19, 2020

\begin{abstract}
The aim of this study was to evaluate the association between number of cavitated dental caries in adolescents and family cohesion, drug use, sociodemographic factors and visits to the dentist. A cross-sectional study was conducted with 746 adolescents aged 15 to 19 years from Campina Grande, Brazil. The parents answered a questionnaire addressing sociodemographic data, and the adolescents answered questionnaires on drug use, type of family cohesion and visits to the dentist. Two examiners underwent training and calibration exercises $(K>0.80)$ to diagnose dental caries using the Nyvad criteria. A directed acyclic graph was created to select the variables to be controlled in the statistical model. Associations between the independent variables and the outcome were determined using robust Poisson Regression analysis for complex samples $(\alpha=5 \%)$. Rate ratios (RR) and 95\% confidence intervals (CI) were calculated. The prevalence of dental caries and cavitated lesions among the adolescents was $92.8 \%$ and $41.6 \%$, respectively. The following variables remained associated with the number of cavitated lesions in the multivariate analysis: disengaged (RR: 6.30; 95\%CI: 1.24-31.88; $p=0.028$ ), separated (RR: 4.80; 95\%CI: 1.03-22.35; $\mathrm{p}=0.046$ ) and connected (RR: 5.23; 95\%CI: 1.27-21.59; $\mathrm{p}=0.024$ ) levels of family cohesion, and high social class (RR: 0.55; 95\%CI: $0.39-0.76 ; p=0.001)$. In conclusion, this paper posits that adolescents with a lower socioeconomic status, and those whose family cohesion was classified as disengaged, separated or connected, had a larger number of cavitated lesions.
\end{abstract}

Keywords: Adolescent; Dental Caries; Family Relations; Social Class.

\section{Introduction}

Adolescence is a period of transition from childhood to adulthood, involving psychological changes and strong social influences, along with greater exposure to risk factors, making it a phase vulnerable to harmful behavior. ${ }^{1}$ According to a systematic review, the prevalence of dental caries among adolescents aged 15 to 19 years, both in Brazil and the rest of the world, ranges from 59 to $90.4 \% .{ }^{2}$ These high rates underscore the importance of studies addressing factors associated with dental caries in this phase of life. Moreover, the most recent national oral health survey ${ }^{3}$ reports that $13.6 \%$ of adolescents have never been to a dentist, a neglectfulness 
that may contribute to the poorer oral health status of this population. Dental visits are important to prevent dental caries and provide proper treatment, and have been associated with a lower prevalence of untreated dental caries in adolescents. ${ }^{2}$.

Adolescents who do not receive socioeconomic support from their families have a greater prevalence of dental caries, probably due to the lack of dental visits and preventive measures. ${ }^{4}$ This underscores the importance of evaluating the association between socioeconomic factors and oral health outcomes in this group. Previous studies have also suggested that a mother's schooling and the number of residents in the home are associated with dental caries. ${ }^{5,6}$ An investigation into these factors is particularly important in developing countries, since the results may vary depending on regional differences.

Associations have also been found between drug use and problems such as poor oral hygiene habits and dental caries, especially in adults, with little attention to adolescents. ${ }^{7,8}$ Therefore, it is important to investigate the influence of drug use on dental caries in adolescents, since substance use is associated with lower adherence to dental treatment in this age group. ${ }^{9}$ Moreover, drug abuse is commonly associated with dental caries, mainly due to neglected self-care and the detrimental effects of drugs on the soft and hard tissues of the oral cavity. ${ }^{8}$

The influence of family cohesion on oral health in adolescents has been little explored in the literature. One study reports an association between poor oral health behavior, dental caries and low family cohesion, but the sample was limited to 15 -year-olds at public schools. ${ }^{10}$ Family cohesion constitutes the emotional ties that family members have with one another. This indicator reflects the level of dependence and independence among the components of a family, and should be studied at different times, since it changes as the adolescent develops. ${ }^{11,12,13}$

Higher levels of family cohesion are believed to contribute to more adequate behavior on the part of adolescents, thereby reducing the likelihood of their developing impulsive and antisocial behavior ${ }^{14}$ and having poor oral health habits. The central hypothesis of this study is that family cohesion is associated with dental caries among adolescents.
Depending on the degree of family cohesion, family members exert a stronger or weaker influence on each other, ultimately affecting beliefs, behaviors and habits. ${ }^{13}$ Thus, strengthening family cohesion is a valuable strategy for promoting the oral health of adolescents. $10,13,14,15$

The aim of the present study was to investigate associations between dental caries and family cohesion, drug use, sociodemographic factors and visits to the dentist among adolescents aged 15 to 19 years. Investigating these associations can contribute to the establishment of preventive policies that are directed at oral issues and that incorporate factors associated with dental practice.

\section{Methodology}

\section{Study design and sample size}

An analytical cross-sectional study was conducted in Campina Grande, a medium-sized city in Brazil. This city has 407,472 residents, with 13,933 adolescents in the target age group ${ }^{16}$. The data collection period was between October 2016 and July 2017. The sample was composed of adolescents aged 15 to 19 years, enrolled in public and private schools in the city of Campina Grande. The sample size was calculated considering a 5\% margin of error, $95 \%$ confidence interval and 50\% prevalence of the condition, to obtain the largest possible sample. Two-stage probabilistic cluster sampling was performed. First, the schools were chosen randomly, and then the students were selected using a simple random sampling method at each school. The sample was proportional to the six administrative districts in the city, to reproduce the characteristics of the population. The minimum sample was determined as 384 adolescents, and was corrected for the study design by applying a factor of 1.6, resulting in 615 adolescents. Finally, $20 \%$ was added to compensate for possible dropouts, yielding a final sample of 769 adolescents.

\section{Eligibility criteria}

This study included literate adolescents between 15 and 19 years old, enrolled in public and private schools in the city of Campina Grande. The exclusion 
criteria were adolescents with cognitive impairment that affected learning and reading (according to parents/guardians or teachers), those wearing orthodontic appliances at the time of the study, and those who still had primary teeth.

\section{Training and calibration exercises}

The Nyvad criteria were used to diagnose the dental caries ${ }^{17}$. Training was conducted in two steps (theoretical and practical). In the theoretical step, an expert in the field performed an in-depth analysis of the diagnostic criteria with two dentists. In the practical step, 50 children were examined and reexamined following a seven-day interval to determine the interexaminer (kappa $=0.89$ to 0.90 ) and intraexaminer (kappa $=0.88$ to 0.90$)$ agreement.

\section{Pilot study}

A pilot study was conducted with 50 adolescents ( 25 from a public school and 25 from a private school). These participants were selected by convenience, and were not included in the main study. The results of the pilot study indicated that there was no need to alter the proposed methods.

\section{Collection of non-clinical data}

The questionnaires were self-administered by the adolescents and their parents/guardians. Meetings were held with the parents/guardians prior to the data collection to clarify the procedures and importance of the study. At this time, the parents answered a questionnaire addressing sociodemographic characteristics (social class, parent's/guardian's age, mother's schooling, adolescent's sex, number of residents in the home and ethnicity). In addition, the adolescents were asked whether they had ever been to a dentist.

The Family Adaptability and Cohesion Evaluation Scales (FACES III) were used to investigate family cohesion, ${ }^{18,19}$ and were answered by the adolescents. FACES III has 10 questions on family cohesion and 10 on family adaptability. The questions are related to daily activities and level of emotional dependence among family members. The sum of the family cohesion questions indicates the adolescent's degree of family cohesion. This instrument establishes fours levels of family cohesion: disengaged - lack of an affective union among family members; separated - moderate affective union among family members; connected - considerable affective union among family members; and enmeshed - maximum affective union among family members. ${ }^{19}$

The Alcohol, Smoking and Substance Involvement Screening Test (ASSIST) developed by the World Health Organization ${ }^{20}$ was employed to evaluate the use of psychoactive substances. The students answered the ASSIST questionnaire in a separate room with no external influences to ensure privacy. The questionnaire addresses licit and illicit drug use, use frequency and risk of psychological disturbance due to drug abuse. It is a self-administered questionnaire with eight items. The item addressing drug use frequency in the previous three months was included in the present study.

\section{Collection of clinical data}

The adolescents brushed their teeth under supervision and received topical fluoride prior to the clinical examinations. They were examined individually in a reserved room, sitting in a school chair in front of the examiner, who was equipped with a head lamp (Petzl Zoom, Petzl America, Clearfield, UT, USA), sterilized mouth mirror (PRISMA, São Paulo, SP, Brazil), sterilized Williams probe (WHO-621, Trindade, Campo Mourão, PR, Brazil) and individual protective equipment. The Nyvad criteria ${ }^{17}$ were used to classify the dental caries, based on the severity of the lesions. These criteria have been validated for use in clinical practice and research in the field of dentistry. The following classification is used, in ascending order: a) active carious lesion on an intact surface; $b$ ) active carious lesion on a discontinuous surface; $\mathrm{c}$ ) active carious lesion with cavitation; d) inactive carious lesion on an intact surface; e) inactive carious lesion on a discontinuous surface; $\mathrm{f}$ ) inactive carious lesion with cavitation; g) restoration in good state; h) restoration with active carious lesion. After the examinations, the adolescents received verbal recommendations regarding oral hygiene, and were instructed to seek dental care at a public service center in their neighborhood, when needed. 


\section{Directed acyclic graph}

A directed acyclic graph (DAG) was created to select covariables for the statistical adjustment, and support the causal interpretation of the effect of exposure on the outcome. DAG is an important tool for reducing bias in epidemiologic studies, since it enables estimating the effect of different independent variables on the outcome, and suggests a minimally sufficient adjustment. Moreover, DAG presents causal directions and facilitates the visualization of the relationships among variables. ${ }^{21}$ Both investigated and uninvestigated variables were incorporated into the model. This step led to the identification of confounding variables that could be controlled in the final model (social class, mother's schooling, number of residents in the home and parent's/guardian's age) (Figure).

\section{Statistical analysis}

Organization of the data and statistical analysis were performed using STATA version 15 (STATA
Corp., College Station, USA). The number of cavitated lesions (Nyvad index) was the dependent variable, and was treated as a discrete numeric variable. Codes 3 and 6 of the Nyvad criteria were used in the present study, since these codes represent the worst possible outcome for dental caries, thereby exerting a greater impact on adolescents. The independent variables were the sociodemographic characteristics, family cohesion, drug use and visits to the dentist. Social class was classified into two categories (low [C, D and E] and high [classes A and B]), based on the Brazilian Economic Classification Criteria. These criteria depend on the number of household appliances, and the householder's education and access to public utility services. They allow a social class to be classified according to five strata (A, B, C, D, and E), based on the estimated average household income ${ }^{22}$. The cutoff for the guardian's age was the median (42 years old). Elementary school (eight years of study) is commonly considered a cutoff point for mother's schooling in Brazil, since it discriminates

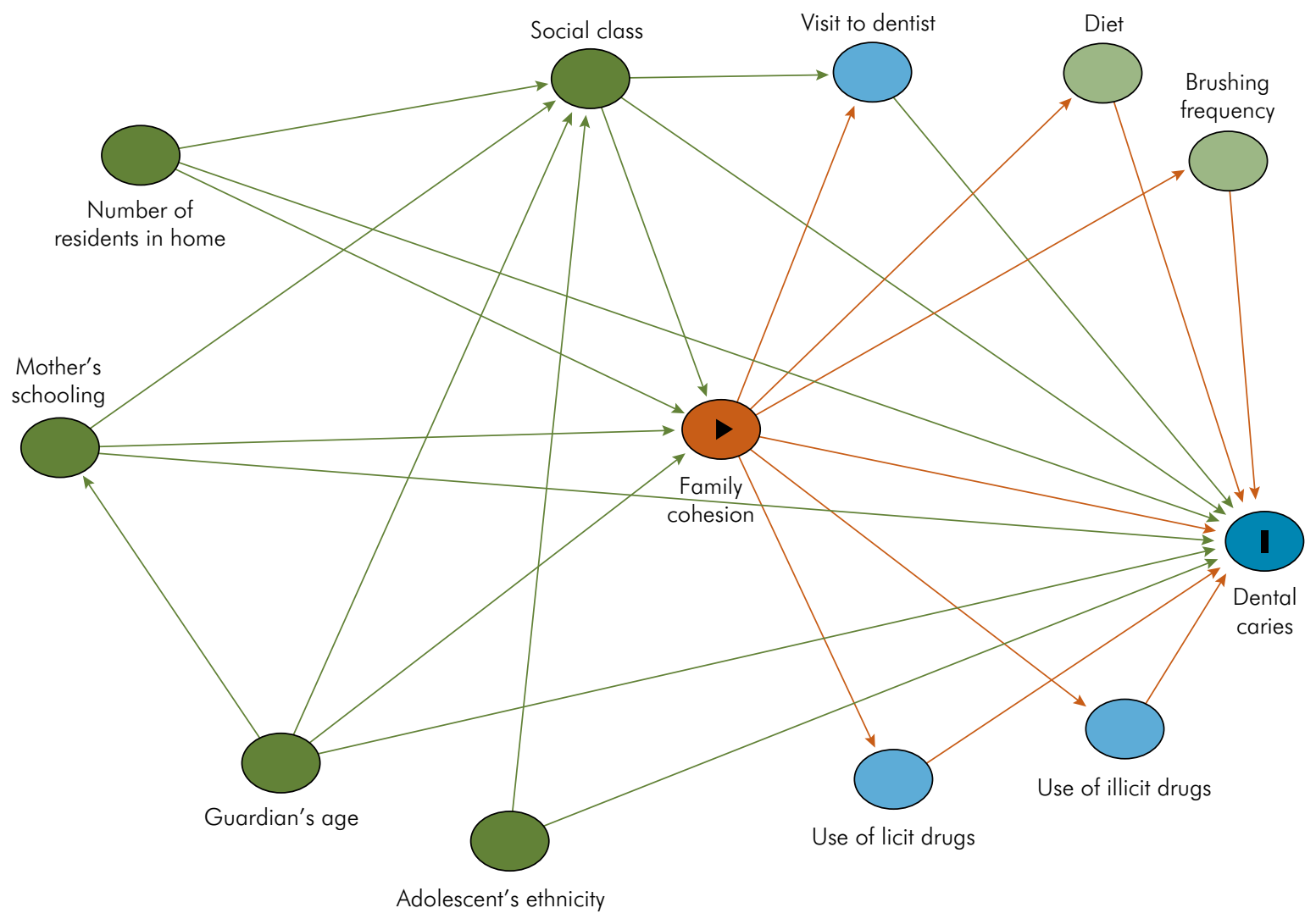

Figure. Directed acyclic graph of factors associated with number of cavitated lesions in adolescents aged 15 to 19 years. 
between low to medium and high levels of education. ${ }^{23}$ Drug use, family cohesion and dental visits were categorized according to the recommendations of the validated questionnaires. ${ }^{3,19,20}$ The association between these variables and the outcome were tested using robust Poisson regression analysis for complex samples. Variables with a p-value $<0.20$ in the bivariate model were incorporated into the multivariate model, and those with a p-value $<0.05$ in the final model were considered as significantly associated with the outcome.

\section{Ethical clearance}

This study received approval from the Human Research Ethics Committee of The State University of Paraiba (certificate number: 55953516.2.1001.5187) and was conducted in accordance with the guidelines established by the Declaration of Helsinki. The parents/ guardians and adolescents agreed to participate by signing a statement of informed consent.

\section{Results}

The final sample was composed of 746 adolescents (response rate: $97 \%$ ). A total of 497 (66.6\%) adolescents attended public schools and 249 (33.4\%) attended private schools. Dropouts were counted as three consecutive failures of adolescents $(n=23)$ to appear on the days scheduled for the examinations. Table 1 shows the characterization of the sample. Most adolescents self-declared themselves as having non-white skin color $(71.7 \%) ; 42.1 \%$ were the eldest child; the female sex accounted for $59.5 \%$ of the sample; the majority lived with up to five people in the home (83.2\%), had been to a dentist at least once in their lifetime (93.8\%) and had mothers who had more than eight years of schooling (59.4\%). Most adolescents reported needing dental treatment $(88.6 \%)$ and $41.6 \%$ had cavitated lesions. A large portion of the adolescents reported disengaged family cohesion (46.1\%).

In the multivariate analysis (Table 2), the variables that remained in the final model were disengaged (RR: 6.30; 95\%CI: 1.24-31.88; $\mathrm{p}=0.028$ ), separated (RR: $4.80 ; 95 \% \mathrm{CI}: 1.03-22.35 ; \mathrm{p}=0,046)$ and connected (RR: 5.23 ; 95\%CI: $1.27-21.59 ; p=0.024$ ) levels of family cohesion; and high social class (RR: 0.55 ; 95\%CI: $0.39-$ $0.76 ; \mathrm{p}=0.001$ ).
Table 1. Characterization of sample.

\begin{tabular}{|c|c|c|}
\hline Variable & $\mathrm{n}$ & $\%$ \\
\hline \multicolumn{3}{|l|}{ Sex } \\
\hline Female & 444 & 59.5 \\
\hline Male & 302 & 40.5 \\
\hline \multicolumn{3}{|l|}{ Ethnicity } \\
\hline White & 211 & 28.3 \\
\hline Non-white & 535 & 71.7 \\
\hline \multicolumn{3}{|l|}{ Birth order } \\
\hline Youngest child & 248 & 33.2 \\
\hline Middle child & 184 & 24.7 \\
\hline Eldest child & 314 & 42.1 \\
\hline \multicolumn{3}{|l|}{ Visit to dentist } \\
\hline Yes & 694 & 93.8 \\
\hline No & 46 & 6.2 \\
\hline \multicolumn{3}{|l|}{ Mother's schooling } \\
\hline$<8$ years of study & 299 & 40.1 \\
\hline$\geq 8$ years of stud & 443 & 59.4 \\
\hline \multicolumn{3}{|l|}{ Social class } \\
\hline Low (C-D-E) & 428 & 57.4 \\
\hline High (A-B) & 318 & 42.6 \\
\hline \multicolumn{3}{|l|}{ Guardian's age } \\
\hline$\leq 42$ years & 384 & 51.6 \\
\hline$>42$ years & 360 & 48.4 \\
\hline \multicolumn{3}{|l|}{ Treatment need } \\
\hline Yes & 597 & 88.6 \\
\hline No & 77 & 11.4 \\
\hline \multicolumn{3}{|c|}{ Number of residents in home } \\
\hline 1 to 5 & 619 & 83.2 \\
\hline 6 or more & 125 & 16.8 \\
\hline \multicolumn{3}{|l|}{ Dental caries } \\
\hline Yes & 692 & 92.8 \\
\hline No & 54 & 7.2 \\
\hline \multicolumn{3}{|l|}{ Cavitated lesions } \\
\hline Yes & 310 & 41.6 \\
\hline No & 436 & 58.4 \\
\hline \multicolumn{3}{|l|}{ Use of licit drugs } \\
\hline Yes & 301 & 40.3 \\
\hline No & 445 & 59.7 \\
\hline \multicolumn{3}{|l|}{ Use of illicit drugs } \\
\hline Yes & 54 & 7.2 \\
\hline No & 692 & 92.8 \\
\hline \multicolumn{3}{|l|}{ Family cohesion } \\
\hline Disengaged & 344 & 46.1 \\
\hline Separated & 266 & 35.7 \\
\hline Connected & 121 & 16.2 \\
\hline Enmeshed & 15 & 2.0 \\
\hline
\end{tabular}


Degree of family cohesion and social class are associated with the number of cavitated dental caries in adolescents

Table 2. Poisson regression for number of cavitated lesions in adolescents, and associated factors.

\begin{tabular}{|c|c|c|c|c|c|c|}
\hline \multirow{3}{*}{ Variable } & \multicolumn{2}{|c|}{$\begin{array}{l}\text { Number of teeth with } \\
\text { cavitated lesions }\end{array}$} & \multicolumn{2}{|c|}{ Bivariate } & \multicolumn{2}{|c|}{ Multivariate } \\
\hline & \multirow{2}{*}{ Mean } & \multirow{2}{*}{$\begin{array}{l}\text { Standard } \\
\text { deviation }\end{array}$} & \multirow{2}{*}{$p$-value } & Unadjusted RR* & \multirow{2}{*}{$p$-value } & Adjusted RR** \\
\hline & & & & (95\% Cl) & & $(95 \% \mathrm{Cl})$ \\
\hline \multicolumn{7}{|l|}{ Social class } \\
\hline Low (C-D-E) & 1.13 & 1.62 & - & 1.00 & - & 1.00 \\
\hline High (A-B) & 0.53 & 1.09 & $<0.001$ & $0.47(0.33-0.67)$ & 0.001 & $0.55(0.39-0.76)$ \\
\hline \multicolumn{7}{|l|}{ Mother's schooling } \\
\hline$<8$ years of study & 1.07 & 1.67 & & 1.00 & - & - \\
\hline$\geq 8$ years of study & 0.73 & 1.26 & 0.012 & $0.65(0.47-0.90)$ & - & - \\
\hline \multicolumn{7}{|l|}{ Guardian's age } \\
\hline$\leq 42$ years & 0.86 & 1.44 & 0.491 & $0.85(0.54-1.34)$ & - & - \\
\hline$>42$ years & 0.88 & 1.46 & & 1.00 & - & - \\
\hline \multicolumn{7}{|l|}{ Ethnicity } \\
\hline White & 0.74 & 1.44 & 0.254 & $0.78(0.51-1.20)$ & - & - \\
\hline Non-white & 0.92 & 1.45 & & 1.00 & - & - \\
\hline \multicolumn{7}{|c|}{ Number of residents in home } \\
\hline 1 to 5 & 0.80 & 1.39 & & 1.00 & - & - \\
\hline$\geq 6$ & 1.16 & 1.67 & 0.266 & $1.26(0.82-1.94)$ & - & - \\
\hline \multicolumn{7}{|l|}{ Use of licit drugs } \\
\hline Yes & 0.82 & 1.42 & 0.470 & 0.87 (0.59-1.27) & - & - \\
\hline No & 0.90 & 1.47 & & 1.00 & - & - \\
\hline \multicolumn{7}{|l|}{ Use of illicit drugs } \\
\hline Yes & 0.96 & 1.65 & & 1.00 & - & - \\
\hline No & 0.86 & 1.43 & 0.329 & $0.81(0.54-1.23)$ & - & - \\
\hline \multicolumn{7}{|l|}{ Family cohesion } \\
\hline Disengaged & 0.98 & 1.55 & 0.017 & $6.70(1.45-30.92)$ & 0.028 & $6.30(1.24-31.88)$ \\
\hline Separated & 0.73 & 1.25 & 0.049 & $4.87(1.00-23.61)$ & 0.046 & $4.80(1.03-22.35)$ \\
\hline Connected & 0.93 & 1.57 & 0.037 & $4.71(1.10-20.10)$ & 0.024 & $5.23(1.27-21.59)$ \\
\hline Enmeshed & 0.27 & 0.45 & & 1.00 & - & 1.00 \\
\hline \multicolumn{7}{|l|}{ Visit to dentist } \\
\hline No & 1.00 & 1.85 & & 1.00 & - & - \\
\hline Yes & 0.86 & 1.42 & 0.557 & $0.87(0.55-1.38)$ & - & - \\
\hline
\end{tabular}

*Unadjusted Poisson regression for independent variables and number of cavitated lesions among adolescents aged 15-19 years, rate ratio (RR) and confidence interval $(95 \% \mathrm{Cl})$; ${ }^{* *}$ Variables incorporated into multivariate model $(\mathrm{p}<0.20)$ : mother's schooling, number of residents in home, family cohesion, social class, guardian's age and ethnicity; (-): variables not selected for final adjusted model ( $p$-value $>0.05$ ); ${ }^{* *}$ Variables incorporated into multivariate model (adjustment factors - directed acyclic graph): social class, mother's schooling, number of residents in home and guardian's age.

\section{Discussion}

In the present study, the prevalence of dental caries in adolescents was high, and the number of cavitated lesions was associated with family cohesion and social class. This is the first study to associate family cohesion and dental caries in a school-based representative sample of adolescents aged 15 to 19 years. The high prevalence of dental caries $(92.8 \%)$ may be related to the diagnostic criteria, which also consider carious lesions in the initial stage (white spots). ${ }^{17}$ This aspect has been observed in previous studies using the same index. ${ }^{24,25,26}$ The Nyvad index is proposed for use in clinical practice and research in dentistry, and can differentiate the various stages of caries, thus making it useful for epidemiological studies.

In the present investigation, a higher social class was associated with fewer cavitated lesions. Previous 
studies report similar findings. ${ }^{4,24,27}$ An individual's cognizance of belonging to a higher social class could exert a positive influence on his access to oral health information and dental services, thereby reducing the dental caries experience. ${ }^{28}$ Moreover, a higher social class may contribute to social cohesion. It has been claimed that social cohesion enhances self-confidence and reduces psychosocial stress, thus leading to better general and oral health behaviors..$^{29,30}$

Drug use was not associated with the number of cavitated lesions among the adolescents, unlike the results reported in previous studies. ${ }^{31,32}$ This likely occurred because drug use may have been considered at some time in life, but may not represent frequency of use. It is important to conduct longitudinal studies considering the frequency of drug use. Another possible explanation for the non-association between drug use and cavitated lesions is the underestimation of drug use. Adolescents may be reluctant to report the truth. ${ }^{33}$ However, for the purposes of the present study, the adolescents answered the ASSIST questionnaire in a separate room with no external influences to ensure privacy.

Regarding family cohesion, the results show that adolescents with low to moderate levels of family union had more cavitated lesions. A previous study found an association between family cohesion and a cariogenic diet in female adolescents ${ }^{15}$. Another study found an association between low levels of family cohesion and dental caries in 15-year-old adolescents enrolled in public schools. ${ }^{10}$ The present investigation included private schools together with public schools, and older adolescents, thus showing that the influence of family cohesion on the number of dental caries continues to be important not only in early but also in late adolescence, and regardless of the type of school. Noteworthily, the present study enabled better representation, compared with the previously cited study.
It is likely that the association between dental caries and family cohesion is mediated by the influence of preventive habits related to dental caries. ${ }^{10,34}$ Thus, a higher degree of family cohesion exerts a positive influence on the prevention of dental caries. The present findings underscore the importance of oral health promotion actions in the school setting, ${ }^{35}$ which take into account socioeconomic and familial factors regarding the prevention of dental caries in adolescents.

The major limitation of the present study was its cross-sectional design, which did not enable a cause-and-effect relationships to be established among the variables analyzed. The strengths of this study were its representative school-based sample, use of validated instruments and calibration of the examiners. Moreover, this study followed the recommendations of the Strengthening the Reporting of Observational Studies in Epidemiology (STROBE) initiative, ${ }^{36}$ and demonstrated the importance of evaluating the influence of family relations on dental caries.

\section{Conclusions}

In conclusion, this paper posited that adolescents with a lower socioeconomic status and those whose family cohesion is classified as disengaged, separated or connected had a larger number of cavitated lesions.

\section{Acknowledgments}

This study received funds from the following Brazilian funding agencies: State of Paraiba Research Assistance Foundation (FAPESQ-PB), State of Minas Gerais Research Assistance Foundation (FAPEMIG), Coordination for the Advancement of Higher Education Personnel (CAPES), and National Council of Scientific and Technological Development (CNPq).

\section{References}

1. Arain M, Haque M, Johal L, Mathur P, Nel W, Rais A, et al. Maturation of the adolescent brain. Neuropsychiatr Dis Treat. 2013;9:449-61. https://doi.org/10.2147/NDT.S39776

2. Reifur KD, Piorunneck CMO, Moyses SJ. Dental caries and treatment needs in adolescents aged 15 to 19 years old and their relationship with dental services: a systematic review. Dent Health Curr Res. 2017 Aug;3:2. https://doi.org/10.4172/2470-0886.1000129 
- Degree of family cohesion and social class are associated with the number of cavitated dental caries in adolescents

3. Ministério da Saúde (BR). Department of Health Surveillance. SB Brazil 2010: national oral health research: main results. 2012 [cited 2019 May 8]. Available from: https://www.saude.gov.br/bucal

4. Fontanini H, Marshman Z, Vettore M. Social support and social network as intermediary social determinants of dental caries in adolescents. Community Dent Oral Epidemiol. 2015 Apr;43(2):172-82. https://doi.org/10.1111/cdoe.12139

5. Saldūnaitè K, Bendoraitienè EA, Slabšinskienè E, Vasiliauskienè I, Andruškevičienè V, Zūbienè J. The role of parental education and socioeconomic status in dental caries prevention among Lithuanian children. Medicina (Kaunas). 2014;50(3):156-61. https://doi.org/10.1016/i.medici.2014.07.003

6. Vazquez FL, Cortellazzi KL, Kaieda AK, Bulgareli JV, Mialhe FL, Ambrosano GM, et al. Individual and contextual factors related to dental caries in underprivileged Brazilian adolescents. BMC Oral Health. 2015 Jan;15(1):6. https://doi.org/10.1186/1472-6831-15-6

7. Shekarchizadeh H, Khami MR, Mohebbi SZ, Ekhtiari H, Virtanen JI. Oral Health of Drug Abusers: A Review of Health Effects and Care. Iran J Public Health. 2013 Sep;42(9):929-40.

8. Baghaie H, Kisely S, Forbes M, Sawyer E, Siskind DJ. A systematic review and meta-analysis of the association between poor oral health and substance abuse. Addiction. 2017 May;112(5):765-79. https://doi.org/10.1111/add.13754

9. Freddo SL, da Cunha IP, Bulgareli JV, Cavalcanti YW, Pereira AC. Relations of drug use and socioeconomic factors with adherence to dental treatment among adolescents. BMC Oral Health. 2018 Dec;18(1):221. https://doi.org/10.1186/s12903-018-0674-4

10. Ferreira LL, Brandão GA, Garcia G, Batista MJ, Costa LS, Ambrosano GM, et al. [Family cohesion associated with oral health, socioeconomic factors and health behavior]. Cien Saude Colet. 2013 Aug;18(8):2461-73. Portuguese. https://doi.org/10.1590/S1413-81232013000800031

11. Jaggers JW, Church WT 2nd, Tomek S, Hooper LM, Bolland KA, Bolland JM. Adolescent development as a determinant of family cohesion: a longitudinal analysis of adolescents in the mobile youth survey. J Child Fam Stud. 2015 Jun;24(6):1625-37. https://doi.org/10.1007/s10826-014-9966-8

12. Santos PL, Bazon MR, Carvalho AM. Family adaptability and cohesion evaluation scale IV (FACES IV): adaptação brasileira. Aval Psicol. 2017;16(2):120-7. https://doi.org/10.15689/AP.2017.1602.01

13. Olson DH, Goral D. Circumplex model of marital and family system. In: Walsh F, ed. Normal family processes: growing diversity and complexity. New York: Guilford; 2003. p. 514-48.

14. Reeb BT, Chan SY, Conger KJ, Martin MJ, Hollis ND, Serido J, et al. Prospective effects of family cohesion on alcoholrelated problems in adolescence: similarities and differences by race/ethnicity. J Youth Adolesc. 2015 Oct;44(10):1941-53. https://doi.org/10.1007/s10964-014-0250-4

15. Franko DL, Thompson D, Bauserman R, Affenito SG, Striegel-Moore RH; National Heart, Lung, and Blood Institute Growth and Health Study (NGHS). What's love got to do with it? Family cohesion and healthy eating behaviors in adolescent girls. Int J Eat Disord. 2008 May;41(4):360-7. https://doi.org/10.1002/eat.20517

16. Instituto Nacional de Estudos e Pesquisas Educacionais "Anísio Teixeira" - INEP. Censo escolar 2014. Brasília, DF: Instituto Nacional de Estudos e Pesquisas Educacionais "Anísio Teixeira, 2014 [cited 2018 October 12]. Available from: http://portal.inep.gov.br/web/guest/censo-escolar

17. Nyvad B, Baelum V. Nyvad criteria for caries lesion activity and severity assessment: a validated approach for clinical management and research. Caries Res. 2018;52(5):397-405. https://doi.org/10.1159/000480522

18. Olson DH, Sprenkle D, Russel C. Circumflex model: systemic assessment and treatment of families. New York: The Harworthpress; 1989.

19. Falceto OG, Busnello ED, Bozzetti MC. [Validation of diagnostic scales of family functioning for use in primary health care services]. Rev Panam Salud Publica. 2000 Apr;7(4):255-63. Portuguese. https://doi.org/10.1590/s1020-49892000000400007

20. Henrique IF, De Micheli D, Lacerda RB, Lacerda LA, Formigoni ML. [Validation of the Brazilian version of Alcohol, Smoking and Substance Involvement Screening Test (ASSIST)]. Rev Assoc Med Bras (1992). 2004 Apr-Jun;50(2):199-206. Portuguese. https://doi.org/10.1590/S0104-42302004000200039

21. Textor J, Hardt J, Knüppel S. DAGitty: a graphical tool for analyzing causal diagrams. Epidemiology. 2011 Sep;22(5):745. https://doi.org/10.1097/EDE.0b013e318225c2be

22. Associação Brasileira de Empresas de Pesquisa - ABEP. Critério Brasil 2015 and social class distribution update for 2016. São Paulo: Associação Brasileira de Empresas de Pesquisa; 2016.

23. Oliveira LB, Moreira RS, Reis SC, Freire MC. Dental caries in 12-year-old schoolchildren: multilevel analysis of individual and school environment factors in Goiânia. Rev Bras Epidemiol. 2015 Jul-Sep;18(3):642-54. https://doi.org/10.1590/1980-5497201500030010

24. Kim JA, Choi HM, Seo Y, Kang DR. Relations among obesity, family socioeconomic status, oral health behaviors, and dental caries in adolescents: the 2010-2012 Korea National Health and nutrition examination survey. BMC Oral Health. 2018 Jun;18(1):114. https://doi.org/10.1186/s12903-018-0576-5

25. Machale PS, Hegde-Shetiya S, Shirahatti R, Agarwal D. Assessment of non-cavitated and cavitated carious lesions among 12- to 15-year-old government and private school children in Pune, Maharashtra, India. Oral Health Prev Dent. 2014;12(2):117-24. https://doi.org/10.3290/i.ohpd.a31659

26. Gushi LL, Soares MC, Forni TI, Vieira V, Wada RS, Sousa ML. [Dental caries in 15-to-19-year-old adolescents in São Paulo State, Brazil, 2002]. Cad Saude Publica. 2005 Sep-Oct;21(5):1383-91. Portuguese. https://doi.org/10.1590/S0102-311X2005000500010 
Dutra LC, Neves ETB, Lima LCM, Gomes MC, Forte FDS, Paiva SM et al.

27. Goenka P, Dutta S, Marwah N, Sarawgi A, Nirwan M, Mishra P. Prevalence of Dental Caries in Children of Age 5 to 13 Years in District of Vaishali, Bihar, India. Int J Clin Pediatr Dent. 2018 Sep-Oct;11(5):359-64. https://doi.org/10.5005/ip-journals-10005-1540

28. Bulgareli JV, Faria ET, Cortellazzi KL, Guerra LM, Meneghim MC, Ambrosano GM, et al. Factors influencing the impact of oral health on the daily activities of adolescents, adults and older adults. Rev Saude Publica. 2018;52:44. https://doi.org/10.11606/S1518-8787.2018052000042

29. Kawachi I, Berkman L. Social cohesion, social capital, and health. In: Berkman L, Kawachi I, editors. Social epidemiology. New York: Oxford University Press; 2000. p. 174-90.

30. Uphoff EP, Pickett KE, Cabieses B, Small N, Wright J. A systematic review of the relationships between social capital and socioeconomic inequalities in health: a contribution to understanding the psychosocial pathway of health inequalities. Int J Equity Health. $2013 \mathrm{Jul} ; 12$ (1):54. https://doi.org/10.1186/1475-9276-12-54

31. Gigena PC, Cornejo LS, Lescano-de-Ferrer A. Oral health in drug addict adolescents and non psychoactive substance users. Acta Odontol Latinoam. 2015 Apr;28(1):48-57.

32. Holmén A, Strömberg U, Magnusson K, Twetman S. Tobacco use and caries risk among adolescentes: a longitudinal study in Sweden. BMC Oral Health. 2013 Jul;13(1):31. https://doi.org/10.1186/1472-6831-13-31

33. Anthony JC, Echeagaray-Wagner F. Epidemiologic analysis of alcohol and tobacco use. Alcohol Res Health. 2000;24(4):201-8.

34. Castilho AR, Mialhe FL, Barbosa TS, Puppin-Rontani RM. Influence of family environment on children's oral health: a systematic review. J Pediatr (Rio J). 2013 Mar-Apr;89(2):116-23. https://doi.org/10.1016/i.jped.2013.03.014

35. Veiga N, Pereira C, Amaral O. Prevalence and determinants of dental caries in a sample of school children of Sátão, Portugal. Rev Port Estomatol Med Dent Cir Maxilofac. 2014 Oct/Dec;55(4):214-9.

36. Malta M, Cardoso LO, Bastos FI, Magnanini MM, Silva CM. STROBE initiative: guidelines on reporting observational studies. Rev Saude Publica. 2010 Jun;44(3):559-65. https://doi.org/10.1590/S0034-89102010000300021 